\title{
ПРОБЛЕМЫ ИСПОЛНИТЕЛЬСКОГО ОСВОЕНИЯ ПОЭТИКИ КАМЕРНО-ВОКАЛЬНЫХ ПРОИЗВЕДЕНИЙ М. МУСОРГСКОГО
}

В работе ставится вопрос о факторах, обусловливающих исключительную трудность исполнительской интерпретации камерно-вокальных произведений М. Мусоргского. Рассматриваются следующие факторы: a) повышенные требования к артикулированию словесного текста песен; б) необходимость привыкания к особенностям музыкального языка композитора; в) необходимость освоения широкого культурного контекста, позволяющего осмыслить темы, проблемы, сюжеты, характер персонажей камерно-вокальных произведений композитора; г) необычность, сложннсть и парадоксальность поэтики творчества М. Мусоргского. Дается рабочее определение понятия «поэтика» музыкального творчества. Намечены некоторые педагогические приемы преодоления выявленных трудностей.

Ключевые слова: Мусоргский, камерная музыка, вокальная музыка, поэтика, словесный текст, музыкальный язык, культурный контекст.

Число исследовательских и публицистических работ, посвященных Модесту Мусоргскому, огромно. Характерно, что интерес к его личности, жизни и творчеству со временем ничуть не снижается. Каждый год в мире публикуются новые статьи и защищаются диссертации на темы, связанные с М. Мусоргским. Это свидетельствует, во-первых, о том, что творческое наследие композитора и его личность неисчерпаемы в плане содержательного и формального богатства, многообразия, оригинальности, а вместе с тем и сложности, проблематичности, можно сказать, даже загадочности. Эти качества привлекают особо пристальное и живое внимание исследователей.

Во-вторых, постоянное расширение круга исследований творчества М. Мусоргского свидетельствует о неугасающем интересе любителей музыки и музыкантов-исполнителей к сочинениям композитора. Действительно, в лучших оперных театрах мира, таких как «Ла Скала», «Гранд Опера», «Ковент Гарден», «Метрополитен Опера», «Большой театр», постоянно ставятся оперы «Борис Годунов» и «Хованщина». Симфоническая поэма «Ночь на Лысой горе» входит в круг самых репертуарных произведений оркестровой музыки. То же самое можно сказать о фортепианном цикле «Картинки с выставки», 
ставшем одной из вершин пианистического искусства XIX века, служащем основой для оркестровых (М. Равель), электронно-звуковых (И. Томита), рок-музыкальных («ЕLР») и др. версий.

На этом фоне мировой популярности произведений М. Мусоргского почти незаметными представляются концертные исполнения его камерно-вокальных произведений: романсов, песен, вокальных циклов. В чем причина? Может быть, произведения этого жанра уступают оперным, симфоническим, фортепианным опусам мастера? Этот вопрос требует всестороннего изучения.

Исследование творчества М. Мусоргского в этом направлении актуально для всех европейских стран, в том числе для России, Украины и Белоруссии, где произведения композитора давно стали неотъемлемой частью высшего слоя музыкальной культуры. Поставленный вопрос имеет многократно большую актуальность для музыкальной культуры Китая. Одной из заметных и важных особенностей современной музыкальной культуры КНР является процесс освоения массовой публикой зарубежной музыки, в первую очередь - жанров и стилей классической европейской традиции. Ранее всего китайцы познакомились с традицией хорового искусства. Затем получила развитие инструментальная сольная и симфоническая музыка. В настоящее время в стране появились оперные театры европейского типа, стала развиваться культура оперного вокала. Лишь в самое недавнее время в художественную практику начало входить камерное вокальное и инструментальное искусство.

Отставание камерной музыки от других жанровых сфер можно объяснить тем, что она требует от слушателей, во-первых, высокоразвитой музыкальности, тонкой восприимчивости, внимательности к малейшим деталям художественного текста, а от исполнителей высокого мастерства, безукоризненной точности воспроизведения формы и артистического таланта. Во-вторых, камерная музыка предполагает самый взыскательный эстетический вкус и обширную общекультурную подготовленность. Следовательно, камерных музыкантов-исполнителей и аудиторию камерных концертов нужно воспитывать, причем на самых лучших образцах камерного искусства. Именно к таковым принадлежат камерно-вокальные произведения Мусоргского. К сожалению, камерная музыка этого автора, почитаемого во всем мире, китайцам практически не известна. Мы не обнаружили в прессе и других источниках ни одного упоминания об исполнении камерно-вокальных произведений М. Мусоргского ки- 
тайскими вокалистами, а также ни одного случая исполнения зарубежным певцом концертной программы, составленной из сочинений композитора.

Эта актуальная практическая проблема требует серьезного внимания исследователей. Необходимо выяснить: в чем причина недостаточного внимания китайских музыкантов-исполнителей, и, вследствие этого, слушателей, к камерно-вокальной музыке Мусоргского? Что мешает этим шедеврам камерного жанра занять достойное место в репертуаре китайских певцов? Какие специфические задачи необходимо решить музыканту-исполнителю в процессе создания успешной интерпретации камерно-вокальных произведений композитора?

Эти конкретные вопросы, насколько нам известно, впервые ставятся в профессиональной музыковедческой литературе. Они должны рассматриваться, как минимум, в трех направлениях: 1) в широком контексте исследований исторической роли творческого наследия М. Мусоргского, его творческого пути, свойств личности, эстетики, поэтики, жанрово-стилевых особенностей и т. д. (Б. Асафьева, Г. Бакаевой, Р. Берченко, Е. Браудо, Д. Брауна, А. Васильевой, К. Дальхауза, Р. Добровенского, В. Каратыгина, М. Кальвокоресси, Л. Керни, Т. Кравченко, Ц. Кюи, Е. Левашова, М. Сокольского, П. Соловьевой, А. Соловцова, О. Соломоновой, В. Стасова, Н. Тетериной, П. Трифонова, Н. Туманиной, С. Тышко, С. Федякина и др.); 2) в контексте историко-культурологических, эстетических и теоретических изысканий, посвященных камерно-вокальной музыке композитора (труды В. Агаву, О. Василенко, В. Васиной-Гроссман, П. ВебераБокхольдта, Н. Вышинской, Л. Гервер, Е. Дурандиной, Е. Нестеренко, Ю. Келдыша, Дж. Линфорда, А. Оголевца, Р. Олдани, М. Расса, О. Рудневой, В. Федорова, Дж. Уокера, К. Эмерсона, В. Яковлева и др.); 3) в связи с психологическими и учебно-методическими проблемами камерного вокального исполнительского искусства.

Цель данной статьи - выявить объективные трудности и наметить соответствующие задачи исполнения камерно-вокальных произведений М. Мусоргского.

Прежде всего следует обратить внимание на те свойства русской камерно-вокальной музыки, которые всегда составляют известную трудность для исполнителей из Китая и других стран.

Первая и, вероятно, наибольшая специфическая трудность исполнения заключается в способности вокалиста правильно воспро- 
изводить звучание словесного текста. Эта проблема не имеет ничего общего с так называемым «языковым барьером». Исполнитель может очень хорошо понимать текст в целом и даже каждое его слово в отдельности. Но озвучивание иностранного текста всегда дается трудно. Это объясняется тем, что каждый язык имеет свой собственный фонетический строй. Если сравнить, к примеру, китайский и русский языки, то окажется, что среди примерно полусотни фонем (о точном количестве фонем ученые ведут споры) в этих двух звуковых комплексах некоторые звуки будут идентичными, некоторые - примерно похожими, а некоторые - совершенно разными. Освоение неродного языка всегда требует привыкания слуха и артикуляционного аппарата к новому фонетическому строю. В этом деле многое зависит от способностей и речевого опыта певца. В любом случае текст каждого нового музыкального произведения на иностранном языке составляет очень значительную специальную трудность для вокалиста. Поэтому в профессиональной деятельности концертирующих певцов во всем мире существует практика подготовки произведений с лингвистом-тренером, работающим специально над произношением словесного текста.

Вероятно, произведения М. Мусоргского составляют в обсуждаемом отношении особо трудную проблему. И не только по той причине, что словесный текст несет чрезвычайно большую смысловую нагрузку. То же самое можно сказать о романсах и песнях других русских композиторов, написанных на слова выдающихся поэтов классико-романтической эпохи (А. Пушкина, М. Лермонтова, А. Толстого, А. Некрасова и др.). Текст всюду важен. Его произнесение в пении должно быть в высшей степени внятным.

Кроме того, в песнях М. Мусоргского словесный текст имеет две важнейшие особенности: а) он служит не только логическим и синтаксическим, но также интонационным основанием для построения мелодии; б) он несет черты заостренной индивидуальности, характеристичности речи; через тонкие специфические свойства речевого поведения «героя» он создает в воображении слушателя его яркий индивидуальный образ.

Таким образом, вокалист должен решить задачу гораздо более сложную, чем только четкое и ясное артикулирование слов песни. Он должен сделать для слушателя ясной индивидуально-неповторимую манеру речи, присущую тому конкретному герою, от лица которого М. Мусоргский высказывается. Здесь вокалист имеет дело не с быто- 
вой, и даже не с ораторской, но с актерской художественной речью. По словам Васиной-Гроссман: «Песни из цикла «Детская», так же как и рассмотренные выше песенки-сценки, требуют совсем особой, актерской манеры исполнения, причем трудность еще увеличивается тем, что взрослый актер-певец должен изображать ребенка» [1, c. 196]. Это свойство подмечали не только исследователи камерного творчества композитора, но и критики, писавшие о концертных исполнениях песен М. Мусоргского (например, В. Стасов [2] и Ю. Энгель [3] по поводу концертов М. Олениной-д’Альгейм, Ф. Шаляпина и др. артистов).

Таким образом, для освоения поэтики камерно-вокальной музыки М. Мусоргского каждый вокалист должен научиться быть актером своеобразной монодрамы, где нет условностей театра: сцены, кулис, декораций, атрибутов, костюма, грима и - главное - контекста драматического действия. Этот контекст вокалист должен создать практически сам (партия фортепиано, конечно, помогает это сделать, но не во всех случаях). Главное условие создания этой монодрамы - apтистическое воспроизведение фонематического строя и артикуляции текста, которые усилены или «приглушены» музыкально-интонационной структурой вокальной партии. В формировании такого умения необходима помощь не только опытного лингвиста, но и тренера по актерскому мастерству. Поэтому реальную помощь в подготовке произведений М. Мусоргского к концертному исполнению может оказать театральный режиссер.

Вторая специфическая трудность работы над произведением неродной музыкальной культуры заключается в знании его музыкального языка. Здесь под музыкальным языком понимается система закономерностей и норм организации звуковых форм (грамматика) и комплекс устойчивых интонационных элементов (лексика). Музыкальные языки разных народов, так же, как и языки словесные, в чемто совпадают, чем-то подобны, а какими-то свойствами значительно отличаются. Скажем, музыкальный язык китайской традиционной культуры значительно отличается от музыкального языка фольклора восточноевропейских народов. Это отличие состоит в строевой организации, метрических системах, звукорядах и ладах, артикуляционных принципах, мелодических и ритмических формулах, типах фактурной и синтаксической организации музыкальной речи.

Освоение европейского музыкального языка представителями азиатских народов в прошлом веке было затруднено изолированно- 
стью их культур. Сегодня этой проблемы не существует. Современные массмедийные средства обеспечили каждому китайцу, начиная с раннего детства, контакт с популярной и классической музыкой Запада. Произведения зарубежной классики изучаются на уроках музыки в общеобразовательной школе. Таким образом, обязательное владение музыкальным языком европейской классической музыки сегодня не является серьезной проблемой для китайского вокалиста, в том числе и для того, кто желает исполнять произведения М. Мусоргского.

Вместе с тем музыкально-выразительный язык произведений М. Мусоргского все же представляет собой известную трудность для каждого исполнителя, чье музыкальное мышление воспитано на образцах классической европейской традиции. Язык композитора ощутимо выделяется оригинальностью, своеобразием, необычностью на фоне музыки его современников. Это отмечали самые авторитетные европейские музыканты его времени, знакомые с произведениями М. Мусоргского (Ф. Лист, К. Дебюсси, М. Равель и др.). Особенностям музыкального языка композитора посвящено множество исследований, в которых выявлено своеобразие метроритма, ладовой организации, интонационной лексики, аккордики, фактуры, синтаксического строения музыкальной речи (работы Т. Бершадской, Г. Головинского, И. Земцовского, О. Рудневой, П. Соловьевой, Е. Трембовельского, Ю. Холопова и др.).

Для того, чтобы привыкнуть к необычным элементам и закономерностям музыкального языка М. Мусоргского, необходимо, прежде всего, прослушать (желательно неоднократно) как можно больше произведений композитора. Еще полезнее - разучить в порядке знакомства ряд его песен, фрагментов из опер. Эффективным способом освоения музыкального языка композитора является аналитическое изучение текстов камерных произведений, опирающееся на специальную литературу (теоретические работы, аналитические экскурсы в монографиях и исторических статьях и т. д.). Основного внимания исполнителя требует ладовая организация, часто приближенная к принципу модальной звуковой системы, а также обусловленная ею гармония. Непривычные уху диссонансы и «жесткие» мелодические ходы становятся понятнее при специальной настройке слуха и голоса на опорный ладовый звукоряд, типичные попевки и созвучия.

Эта сторона подготовки певца к освоению камерно-вокальных произведений М. Мусоргского требует целенаправленных усилий педагога и, в связи с этим, серьезной методической разработки от- 
меченной музыкально-речевой проблемы. Свою пользу могла бы принести небольшая хрестоматия, включающая в себя не сложные, но наиболее характерные для музыкального языка М. Мусоргского фрагменты из его произведений.

Третья и, как мы полагаем, наибольшая трудность связана с пониманием художественно-образного содержания произведений. Мы исходим из следующего теоретического положения: любое музыкальное произведение всегда в какой-то степени понятно каждому человеку. Полное непонимание содержания произведения искусства явление теоретически невозможное. В этом феномене проявляется основная специфика художественно-образного способа отображения действительности. Вместе с тем понимание и - соответственно - интерпретация произведения искусства зависит от того - как именно, и в какой степени произведение понятно исполнителю. Качество и уровень понимания (иногда эти стороны можно разграничить, а иногда - нет) зависят от ряда факторов.

Самый важный из них - это жизненный и художественный опыт музыканта. Жизненный опыт студента-вокалиста обсуждать не будем. Он не поддается типологическому рассмотрению. Это и не требуется. Все равно необходимый для постижения творчества М. Мусоргского опыт жизни невозможно целенаправленно формировать, направлять, дополнять в процессе профессиональных занятий вокалом.

Другое дело - художественный опыт. Он может и должен целенаправленно и планомерно создаваться в процессе обучения искусству камерного пения.

К художественному опыту, наиболее существенному для восприятия и интерпретации образного содержания камерно-вокальных произведений М. Мусоргского мы относим, во-первых, знания о русской жизни в XIX веке в разных ее проявлениях. Наиболее важны знания в сферах истории народа, устройства общества, повседневного быта крестьян, мещан, дворянства, разночинцев. Необходимо иметь хотя бы общие представления о восточном христианстве, о церкви и мирянах, основных догматах и ритуалах Православия. Особенно важны знания о народном и профессиональном искусстве, в первую очередь - музыкальном.

Во-вторых, понимание песен М. Мусоргского требует не обязательно глубокого, но конкретно-опытного знания классико-романтической традиции камерно-вокальной музыки XIX века в самых ярких ее проявлениях (камерные кантаты И. С. Баха, песни Й. Гайд- 
на, В. Моцарта, Л. Бетховена, Ф. Мендельсона, Р. Вагнера, Ф. Листа, Э. Грига, романсы и песни М. Глинки, Ц. Кюи, Н. Римского-Корсакова, А. Бородина, П. Чайковского). Особого внимания при подготовке к интерпретации песен М. Мусоргского достойны произведения тех авторов, которые решали сходные с ним творческие задачи, наметившие особую жанровую разновидность камерно-вокального произведения, а именно - стихотворение с музыкой. Речь идет о произведениях Ф. Шуберта, Р. Шумана, Г. Вольфа, А. Даргомыжского.

В-третьих, весьма желательны знания о композиторе как личности, в частности о его жизненном пути, этапах освоения музыкального искусства, характере, мировоззрении, мироощущении, идеях, наставниках, друзьях, сотрудниках, противниках, критиках и т. д. Сложность проблемы состоит в том, что такого рода знания нужны не в виде фактов и научно достоверных суждений. Необходимы конкретно-чувственные, образные, эмоционально окрашенные, лично пережитые и оцененные знания. Важно именно это качество знаний, а не их объем. Такого рода знания содержатся в самом искусстве и художественной литературе. Это обстоятельство ставит перед преподавателями музыкальных вузов особую учебно-методическую задачу - составление рекомендаций относительно тех литературных и художественных источников, которые способствуют направленному расширению культурного горизонта и непосредственно готовят к исполнению камерно-вокальных произведений М. Мусоргского. Так, например, к ряду дидактически целесообразных источников необходимой молодому музыканту-исполнителю информации можно отнести монографии о жизни и творчестве композитора в популярном изложении (Е. Абызовой, А. Альшванга, А. Орловой, Г. Хубова, Э. Фрид и др.); художественный фильм «Мусоргский» (Г. Рошаль, 1950 г.); критические статьи (Б. Асафьева, Ц. Кюи, В. Стасова, Ю. Энгеля и др.), в которых есть суждения не только о произведениях композитора, но также и об их исполнении выдающимися артистами. Музыкантаминтерпретаторам, особенно зарубежным, полезно познакомиться с репродукциями картин В. Перова, И. Репина, И. Крамского, И. Прянишникова, Н. Неврева, В. Максимова, Г. Мясоедова, Н. Ярошенко, В. Сурикова, Н. Ге, В. Маковского, М. Нестерова. Заслуживают внимания также скульптурные работы М. Антокольского и С. Коненкова; репродукции графических работ Н. Гартмана, иллюстрации к «Физиогномике» Иоганна Лафатера (известен глубокий интерес композитора к этому труду). 
Наконец, четвертая трудность, которую необходимо преодолеть исполнителю для достижения художественно ценной интерпретации, заключается в осмыслении и творческом освоении уникальной поэтики М. Мусоргского.

Для прояснения этого вопроса необходимо условиться о значении термина «поэтика». Сегодня это слово чаще всего используют филологи, обозначая «раздел теории литературы, изучающий структуру поэтического произведения, поэтическую форму, приемы поэтического искусства, принципы его анализа. Термин «поэтика» нередко переносится на самый объект изучения: например, «поэтика Пушкина» [2, c. 241]. Вслед за Аристотелем, благодаря которому это слово получило значение общенаучного термина, будем понимать «поэтику» как комплекс знаний о том, как устроено произведение искусства, какими средствами, способами, приемами достигнута способность созданной автором формы оказывать воздействие на сознание людей, способность порождать эмоциональный отклик, вызывать эстетическую оценку, пробуждать ассоциации, стимулировать процесс мышления.

Поэтика - системное качество творческой деятельности и художественного сознания. Во-первых, поэтика охватывает и объединяет все стороны и уровни устройства формы. Если речь идет о музыкальной поэтике, то ее слагаемыми выступают все многочисленные и иерархически организованные свойства формы: звуковой материал, музыкальный язык (звуковысотный строй, метроритм, лад, артикуляционная и динамическая системы), музыкальная композиция (синтаксис, фактурное устройство, логика тематического устройства). Во-вторых, поэтика включает в себя технику и технологию сочинения, комплексы приемов творчества (например, техники подвижного контрапункта, фигурирования аккордов и др.). Поэтика в значительной степени зависит от эстетических и этических особенностей сознания композитора, от его мировосприятия и миропонимания. Наконец, поэтика в каждом конкретном случае определяется закономерностями музыкальных и общехудожественных стилей и жанров.

Почему поэтика М. Мусоргского, в частности - камерно-вокальных сочинений композитора трудна для понимания и воплощения? Ответ на этот вопрос требует обстоятельного исследования. Здесь отметим лишь наиболее очевидные факторы сложности.

Прежде всего, камерно-вокальные произведения М. Мусоргского отличаются своеобразным отношением к эстетическим качествам вокала. Композитор естественно, а иногда и нарочито, ограничивает 
возможности исполнителя продемонстрировать самые лучшие свойства своего голоса: широту диапазона, яркость, мощь, легкость, «тембристость». Все те свойства музыкального текста, которые разработаны в мировой композиторской практике для демонстрации вокальной виртуозности, М. Мусоргского как будто вообще не интересуют. В его песнях и романсах почти нет мелизматических украшений, ярких пассажей, нет патетических удержаний звука на фермате - всего того, что восхищает массового слушателя и дает возможность певцу обнаружить исключительные достоинства своего голоса. Уже только одно это обстоятельство способно обескуражить певцов, сбить их с толку и отвратить их симпатии от музыки М. Мусоргского.

Следующая черта поэтики композитора, вызывающая серьезные затруднения исполнителей, состоит в том, что М. Мусоргский не просто лишает музыкальную форму привычных вокальных красот. Он отваживается на гораздо более радикальный шаг. В ряде случаев он обращается к образам, находящимся как бы за гранью красоты. Он вторгается в художественно-семантическую область страшного, уродливого, отвратительного, психически ненормального (образы смерти, тяжелой болезни, крайнего уныния, галлюцинаций, маниакального психоза и др.). Во всей мировой музыкальной литературе найдется очень мало произведений такого рода.

Еще одна черта поэтики М. Мусоргского - парадоксальность. Его образы часто несут отпечаток взаимоисключающей двойственности. Очевидный пример: образ Смерти как действующего лица в цикле «Песни и пляски смерти». В этом образе (по крайней мере в трех песнях) неразделимо соединились конфликтующие смыслы: смерть как абсолютное зло, прерывающее высшее благо жизни, и смерть как акт добра и милосердия, как избавление от жизненных страданий. Этот антагонизм труден даже для логического рассуждения. А как его представить в исполнении?

Проблема осмысления и практического освоения парадоксальной поэтики М. Мусоргского возникает перед исполнителем каждого камерно-вокального произведения композитора. Противоречивое единство пессимистических настроений и оптимизма, натуралистического взгляда на мир и мистицизма, лирической тонкости и эпической грубости, романтизма и критического реализма придают поэтике мастера исключительно сложный характер. Очевидно, что освоение поэтики М. Мусоргского требует от исполнителя зрелого ума, способности к философской рефлексии. Трудно надеяться на 
то, что эта поэтика будет вполне понята и практически освоена начинающим вокалистом. Однако при настойчивой пытливости, при работе под руководством опытного музыканта-наставника, будущий артист может с самого начала процесса обучения камерному вокалу начать движение к осмыслению поэтического мира М. Мусоргского. Наградой певцу будет постижение глубокого богатого мира образов композитора, овладение высшим уровнем художественного мастерства, когда у исполнителя появляется способность увлекать слушателей не столько красотой звуков, сколько красотой образов и глубиной смыслов.

Разумеется, затронутые в статье особенности поэтики камерновокальных произведений М. Мусоргского и методики ее освоения требуют дальнейшего исследования и отдельной печатной репрезентации.

\section{СПИСОК ЛИТЕРАТУРЫ}

1. Васина-Гроссман В. Русский классический романс XIX века / В. Васина-Гроссман. - М. : Изд-во АН СССР, 1956. - 352 с.

2. Стасов В. Избранные сочинения. Живопись, скульптура, музыка : в 3 т. / В. В. Стасов. - М. : Искусство, 1952. - Том 3.

3. Энгель Ю. Глазами современника. Избранные статьи о русской музыке 1898-1918 / Ю. Д. Энгель. - М. : Сов. композитор, 1971. - 534 с.

4. Энциклопедический словарь : в 2 т. Т. 2. - М.: Сов. Энциклопедия, 1964.

Лю Нань. Проблеми виконавської освоєння поетики камерно-вокальних твоpiв М. Мусоргського. У роботі ставиться питання про фактори, що обумовлюють виняткову складність виконавської інтерпретації камерно-вокальних творів М. Мусоргського. Розглядаються наступні фактори: а) підвищені вимоги до артикуляції словесного тексту пісень; б) необхідність звикання до особливостей музичної мови композитора; в) необхідність освоєння широкого культурного контексту, що дозволяє осмислити теми, проблеми, сюжети, характер персонажів камерно-вокальних творів композитора; г) незвичайність, складність і парадоксальність поетики М. Мусоргського. Дається робоче визначення поняття «поетика» музичної творчості. Намічено деякі педагогічні прийоми подолання виявлених труднощів.

Ключові слова: Мусоргський, камерна музика, вокальна музика, поетика, словесний текст, музична мова, культурний контекст.

Liu Nan. Problems of interpretation of Musorgsky's chamber vocal music. In work the question on the factors causing exclusive difficulty of interpretation of Musorgsky's chamber vocal works is discussed. The following factors are examined: a) in- 
creased requirements to an articulation of the verbal text of songs; б) necessity of accustoming to features of composer's musical language; в) necessity of development of a wide cultural context allowing to comprehend of themes, problems, plots, characters in Musorgsky's chamber vocal works; г) singularity, complexity and paradoxicality of composer's poetics. The working definition of «poetics» as a musicological term is given. Some pedagogical receptions of overcoming of the revealed difficulties are planned.

Keywords: Musorgsky, chamber music, vocal music, poetics, verbal text, musical language, cultural context.

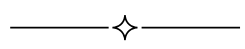

УДК 78.01/78.05+782.1

\title{
Чжан Кай
}

\section{ЖАНРОВО-ЭСТЕТИЧЕСКИЕ ПРЕДПОСЫЛКИ ВОКАЛЬНО-ИСПОЛНИТЕЛЬСКОЙ ИНТЕРПРЕТАЦИИ ОПЕРНОГО ОБРАЗА}

\begin{abstract}
В статье определяются основные жканрово-коммуникативные $и$ художественно-знаковые параметры оперы, условия создания особого оперного художественно-видового синтеза. Обнаруживается исполнительская природа данного синтеза, с одной стороны, особый сложнофункционально-иерархический характер оперного исполнительства, с другой. Освещаются необходимые профессионально-личностные качества оперного вокального исполнителя.
\end{abstract}

Ключевые слова: оперный жанр, синтетическая исполнительская форма оперы, оперная поэтика, оперный темпоритм, вокально-исполнительская интерпретация.

История оперного жанра свидетельствует о том, что в основе этой разновидности музыкально-театрального искусства находится dramma per musica, следовательно, драматическое действие, выражению которого сопутствует и содействует музыкальное начало. Сценическая действие с присущей ему визуально-зрелищной стороной - ведущий процесс для любой театрально-жанровой формы. Рождение оперы неотдалимо от становления театрального искусства в его целостности, то есть от театральности как важной доминанты культуры, пришедшей на смену храмовости, обусловившей особый интерес к человеку и его переживаниям, то есть подразумевающей процесс интимизации образных значений.

(C) Чжан Кай, 2015 